\title{
Mechanical and nanomechanical properties of MWCNT/PP nanocomposite
}

\author{
K.I. Tserpes, A. Chanteli, Sp. Pantelakis \\ Department of Mechanical Engineering \& Aeronautics, University of Patras, Laboratory of Technology \& Strength of Materials, \\ Patras 26500, Greece \\ kitserpes@upatras.gr,aggelikichanteli@gmail.com,pantelak@upatras.gr \\ E.P. Koumoulos, C.A. Charitidis \\ RNanolab, National Technical University of Athens, School of Chemical Engineering, 9 Heroon Polytechniou St., Zographos, \\ Athens, 15780, Greece \\ elikoum@chemeng.ntua.gr,charitidis@chemeng.ntua.gr
}

\begin{abstract}
The mechanical and nanomechanical properties of multi-walled carbon nanotube-reinforced polypropylene (MWCNT/PP) nanocomposite were investigated through tension tests (conducted on $2 \mathrm{wt} \%$ and $5 \mathrm{wt} \%$ specimens) and nanoindentation tests (conducted on $2 \mathrm{wt} \%$ specimens). In addition, the structural properties and topography of the nanocomposite were characterized by means of scanning electron microscopy (SEM) and Scanning Probe Microscopy (SPM), respectively. The results from the tension tests reveal an enhancement and a considerable scatter in the Young's modulus and maximum stress of the MWCNT/PP nanocomposite for both MWCNT content. For the specimens with mechanical properties lower than the average values, the SEM and SPM images revealed poor dispersion and formation of large agglomerates. The hardness (as resistance to applied load) and Young's modulus were mapped at $300 \mathrm{~nm}$ of displacement, for a grid of $70 \times 70 \mu \mathrm{m}^{2}$. Through projection, the resistance is clearly divided into 3 regions, namely the PP matrix, the interphase (region close to/between MWCNTs) and the regions of the MWCNT agglomerates. The resistance deviates from low values (few $\mathrm{MPa}$ ) to $1.8 \mathrm{GPa}$. The present experimental study provides all necessary data for the model creation and validation of the MWCNT/PP nanocomposite.
\end{abstract}

KEYWORDS. Polypropylene nanocomposite; Young's modulus; Nanoindentation; Carbon nanotubes.

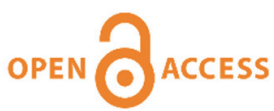

Citation: Tserpes, K.I., Chanteli, A., Pantelakis, Sp., Koumoulos, E.P., Charitidis, C.A., Mechanical and nanomechanical properties of MWCNT/PP nanocomposite, 46 (2018) 73-83.

Received: 07.03.2018

Accepted: 25.03.2018

Published: 01.10.2018

Copyright: (C) 2018 This is an open access article under the terms of the CC-BY 4.0, which permits unrestricted use, distribution, and reproduction in any medium, provided the original author and source are credited. 


\section{INTRODUCTION}

$\mathrm{T}$ he extraordinary properties of carbon nanotubes (CNTs) offer the ability of manufacturing polymers with enhanced mechanical properties at low concentrations of the nanofiller in comparison with the use of other additives, such as carbon black, which requires higher concentrations for an effective reinforcement. Indeed, if the desired performance can be achieved at low concentrations, novel lightweight materials can be fabricated, to be used in a range of advanced applications such as aerospace structures.

To obtain the desired properties in the nanocomposite material, it is important to achieve a homogeneous and uniform dispersion of CNTs in the matrix, having in parallel a strong interfacial bonding between the two phases (organic and inorganic) [1,2]. However, the chaotic entanglement of CNTs can lead to the formation of agglomerates in the scale of micrometers [3-5]. Generally, multi-wall CNTs (MWCNTs) are easier to disperse in polymer matrices, as they have larger diameters, in comparison with single-wall CNTs (SWCNTs). Carbon nanotubes have been distinguished from other nanomaterials, due to their extraordinary electrical properties. Several studies have investigated also the mechanical properties of such composites, focusing on the elasticity [6], tribology [7], toughness [8] and damage [9] of the specimens. Nanomechanical measurements, through nanoindentation, have also been used for the assessment of the mechanical properties of nanocomposites based on epoxy resin, reinforced with SWCNTs [10].

Among thermosets, epoxy resins have been very often studied as a potential matrix for nanocomposites with CNTs. Small quantity of CNTs, often between 0.1 and $5.0 \%(\mathrm{w} / \mathrm{w})$, is added to the polymeric matrix aiming to improve mechanical and thermal properties [11]. Li et al. [12] studied the nanomechanical properties of SWCNTs reinforced epoxy composites with varying weight percentage $(0,1,3$, and $5 \mathrm{wt} \%)$ via the nanoindentation and nanoscratch techniques; the addition of $5 \mathrm{wt} \%$ SWCNTs increased the elastic modulus by $75 \%$ and the hardness by $30 \%$ when compared to the pure epoxy. An improvement by $80 \%$ in tensile modulus was obtained when thermoplastic poly(vinyl alcohol) (PVA) was mixed with only 1wt. $\%$ CNTs [13]. An increase of $28 \%$ in tensile Young's modulus was observed in the rubbery system using $1 \mathrm{wt} \%$ functionalized nanotubes, compared to the unreinforced rubbery epoxy [14]. Based on nanoindentation tests, improvements of hardness by $18 \%$ and $36 \%$ for polypropylene/CNTs composite (1 and 3\%, respectively) are reported [15], compared to that of neat PP; additionally, the stiffness increased from 1.22 GPa (neat PP) to $1.47 \mathrm{GPa}(20.5 \%)$ and $1.64 \mathrm{GPa}(34.4 \%)$ for 1 and 3\% w/w respectively, while creep rate and displacement of the nanocomposites were lower than the neat PP [15]. Despite the large number of published experimental works, there is still the necessity for detailed characterization of the morphology, the mechanical and nanomechanical behavior of CNT/polymer nanocomposites in order to clearly understand the load transfer mechanisms between MWCNTs and polymers (thermosets and thermoplastics) and correlate the material structure with the mechanical properties of the nanocomposites. In the present work, the mechanical and nanomechanical properties of multi-walled carbon nanotube-reinforced polypropylene (MWCNT/PP) nanocomposite were investigated through tension tests (conducted on $2 \mathrm{wt} \%$ and $5 \mathrm{wt} \%$ specimens) and nanoindentation tests (conducted on $2 \mathrm{wt} \%$ specimens).

\section{EXPERIMENTAL}

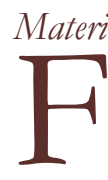

Materials

$\mathrm{F}$

or the study, the Plasticyl ${ }^{\mathrm{TM}}$ PP2001 [16] material was used. Because of its low viscosity and high flow formulation, the Plasticyl PP2001 material it is ideal for standard injection molding and extrusion processes. Additional benefits of the specific materials are the enhanced electrical conductivity at low loading, retention and/or improvement of key mechanical properties and easier processing. The Young's modulus of the neat Polypropylene (PP) material is reported to be $1280 \mathrm{MPa}$ [17] and the tensile strength at break $28.2 \mathrm{MPa}[17]$.

\section{Tension tests}

The tension tests on the reference PP and MWCNT/PP specimens were conducted according to the ASTM D638 standard [17] at room temperature using the electro-mechanical testing machine Tinius Olsen H5KT which incorporated a tension/compression transducer with a load-cell of $1 \mathrm{kN}$. The tests were conducted at a crosshead speed of $1 \mathrm{~mm} / \mathrm{min}$. For each test set, 6 specimens were tested.

\section{SEM tests}

Scanning electron microscopy (SEM) tests were conducted using a LaB6 electron gun integrated with an e-beam lithography system to characterize the morphology of the MWCNT/PP nanocomposite. The technical data of the microscopy are: 30 
$\mathrm{kV}$ accelerating voltage, $3 \mathrm{~nm}$ resolution, 300.000 magnification, $1 \mathrm{pA}-1 \mu \mathrm{A}$ beam current, 5 axis X-Y-Z-R-T stage and low vacuum mode for non-conductive sample observation.

\section{Nanoindentation tests}

Nanomechanical integrity of the materials is assessed through a Hysitron TriboLab ${ }^{\circledR}$ Nanomechanical Test Instrument, which also operates as Scanning Probe Microscope (SPM) and allows the application of loads from $1 \mu \mathrm{N}$ to $30 \mathrm{mN}$, recording the displacement as a function of applied loads with a high load resolution $(1 \mathrm{nN})$ and a high displacement resolution $(0.04 \mathrm{~nm})$. In all measurements, a total of 10 indents are averaged so as to determine the mean hardness $(\mathrm{H})$ and elastic modulus $(E)$ values for statistical reasons in a clean area environment with $45 \%$ humidity and $23{ }^{\circ} \mathrm{C}$ ambient temperature. In order to operate under closed loop control, feedback control option was selected. All measurements have been performed using the standard three-sided pyramidal Berkovich tip indenter, with an average curvature radius of 100 $\mathrm{nm}[18,19]$.

Considering the half-space elastic deformation theory, $H$ and $E$ values can be calculated from the experimental data (load displacement curves) using the Oliver-Pharr (O\&P) model [20,21]. The derived expressions for calculating E extracted from indentation measurements are based on Sneddon's elastic contact theory:

$$
E_{r}=\frac{S \sqrt{\pi}}{2 \beta \sqrt{A_{c}}}
$$

where $S$ is the unloading stiffness (initial slope of the unloading load-displacement curve at the maximum displacement of penetration (or peak load)), $A_{c}$ is the projected contact area between the tip and the substrate and $\beta$ is a constant that depends on the geometry of the indenter $(\beta=1.167$ for Berkovich tip [22,23]). Typical nanoindentation hardness refers to the mean contact pressure required. This hardness, which is the contact hardness $\left(H_{c}\right)$, is actually dependent upon the area geometry of the tip indenter and is given by

$$
H_{c}=\frac{F}{A}
$$

where

$$
A\left(h_{c}\right)=24.5 h_{c}^{2}+a_{1} b_{c}+a_{1 / 2} b_{c}^{1 / 2}+\ldots+a_{1 / 16} b_{c}^{1 / 16}
$$

and

$$
h_{c}=h_{m}-\varepsilon \frac{P_{m}}{S_{m}}
$$

where $h_{m}$ is the total penetration displacement of the indenter at peak load, $\mathrm{P}_{\mathrm{m}}$ is the peak load at the indenter displacement $h_{m}$, and $\varepsilon$ is an indenter geometry constant, equal to 0.75 for Berkovich indenter [24, 25]. Prior to indentation, the area function of the indenter tip was calibrated in a fused quartz/silica (standard material) [26].

\section{EXPERIMENTAL RESULTS}

\section{Mechanical properties and SEM tests}

7 he recorded engineering stress-strain curves are depicted in Fig. 1. The plotted strain was evaluated by the ARAMIS system at the center of the specimen and the plotted stress was derived from the load recorded by the load-cell of the machine. The curves are displayed up to the strain of 0.3. Failure of the specimens was reached at much higher strains.

The reference material exhibits a non-linear behavior from the start and the curves of the reference specimens show a small scatter. For the nanofilled material, a clear enhancement in the Young's modulus and maximum stress is obtained. 
Differentiation of the curves of the MWCNT/PP $2 \mathrm{wt} \%$ and $5 \mathrm{wt} \%$ materials is not obvious due to the large scatter. Tab. 1 lists the Young's moduli and maximum stress for each specimen. The Young's modulus has been computed using the measurements from the strain gauges. The comparison between the average values of the properties reveals a significant increase in both the Young's modulus and maximum stress of the nanofilled material. The increase is greater for the maximum stress. In addition, the comparison between the $2 \mathrm{wt} \%$ and $5 \mathrm{wt} \%$ materials reveals clearly that the larger content of MWCNTs leads to a larger increase in the properties of the PP material something that is not obvious in the stress-strain curves.

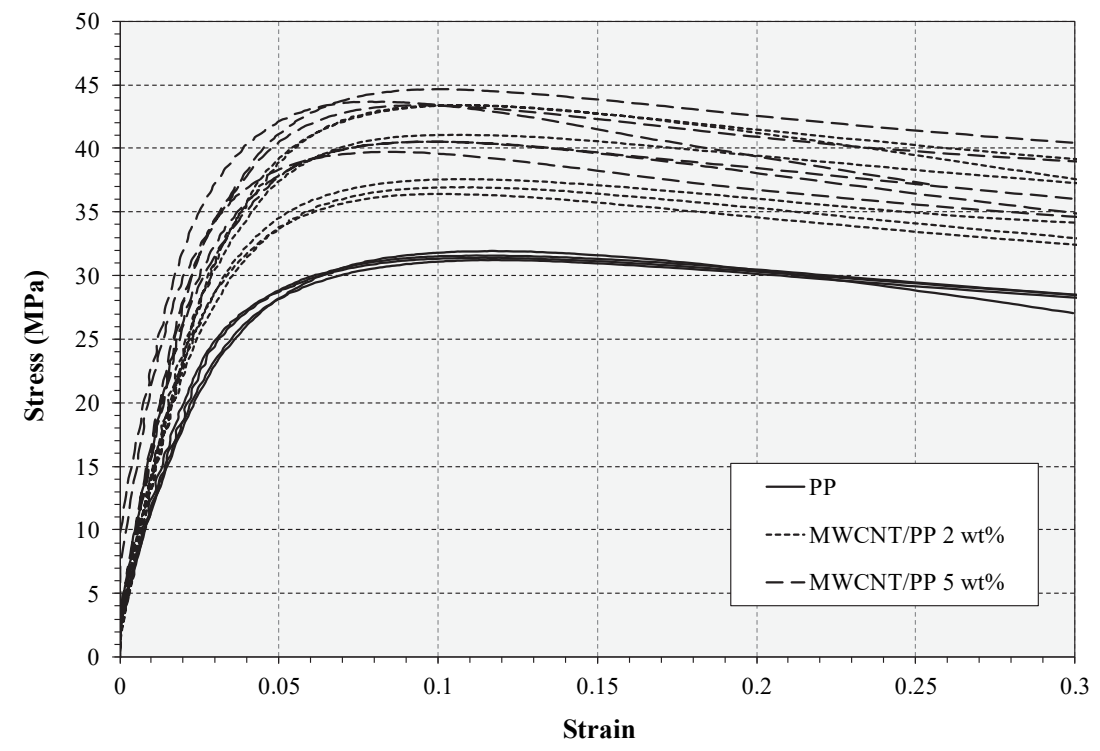

Figure 1: The stress-strain curves measured by the ARAMIS system for all tests.

\begin{tabular}{|c|c|c|c|c|}
\hline Specimen & $\begin{array}{l}\text { Young's } \\
\text { modulus }(\mathrm{MPa})\end{array}$ & $\begin{array}{l}\text { Maximum } \\
\text { stress }(\mathrm{MPa})\end{array}$ & $\begin{array}{l}\text { Average Young's } \\
\text { modulus } \\
\text { (standard } \\
\text { deviation) }\end{array}$ & $\begin{array}{l}\text { Average } \\
\text { maximum stress } \\
\text { (standard } \\
\text { deviation) }\end{array}$ \\
\hline PP_01 & 1629.2 & -1 & \multirow{6}{*}{$1641.33(85.75)$} & \multirow{6}{*}{31.55 (0.33) } \\
\hline PP_02 & 1515.6 & -1 & & \\
\hline PP_03 & 1592,0 & 31.22 & & \\
\hline PP_04 & 1767.6 & 31.40 & & \\
\hline PP_05 & 1687.9 & 31.98 & & \\
\hline PP_06 & 1657.5 & 31.61 & & \\
\hline MWCNT 2 wt\%_01 & 1885.2 & 41.06 & \multirow{6}{*}{$1974.73(146.7)$} & \multirow{6}{*}{$39.80(3.22)$} \\
\hline MWCNT/PP 2 wt\%_02 & 2092.1 & 43.36 & & \\
\hline MWCNT/PP 2 wt $\% \_03$ & 2057.3 & 43.41 & & \\
\hline MWCNT/PP 2 wt\%_04 & 2007.8 & 36.43 & & \\
\hline MWCNT/PP 2 wt\%_05 & 2086.8 & 36.94 & & \\
\hline MWCNT/PP 2 wt $\%$ _06 & 1719.2 & 37.57 & & \\
\hline MWCNT/PP 5 wt $\%$ _01 & 2175.3 & 44.61 & \multirow{6}{*}{2055.22 (121.82) } & \multirow{6}{*}{$42.06(2.06)$} \\
\hline MWCNT/PP 5 wt\%_02 & 1965.8 & 40.54 & & \\
\hline MWCNT/PP 5 wt \%_03 & 1912.4 & 40.49 & & \\
\hline MWCNT/PP 5 wt \%_04 & 2182.9 & 43.38 & & \\
\hline MWCNT/PP 5 wt\%_05 & 2039.7 & 43.68 & & \\
\hline MWCNT/PP 5 wt\%_06 & $2075.2^{2}$ & 39.68 & & \\
\hline
\end{tabular}

Table 1: Measured mechanical properties of the PP and nanocomposite.

${ }^{1}$ No data are available from the ARAMIS system

${ }^{2}$ Estimated from the ARAMIS system due to strain gauge failure. 

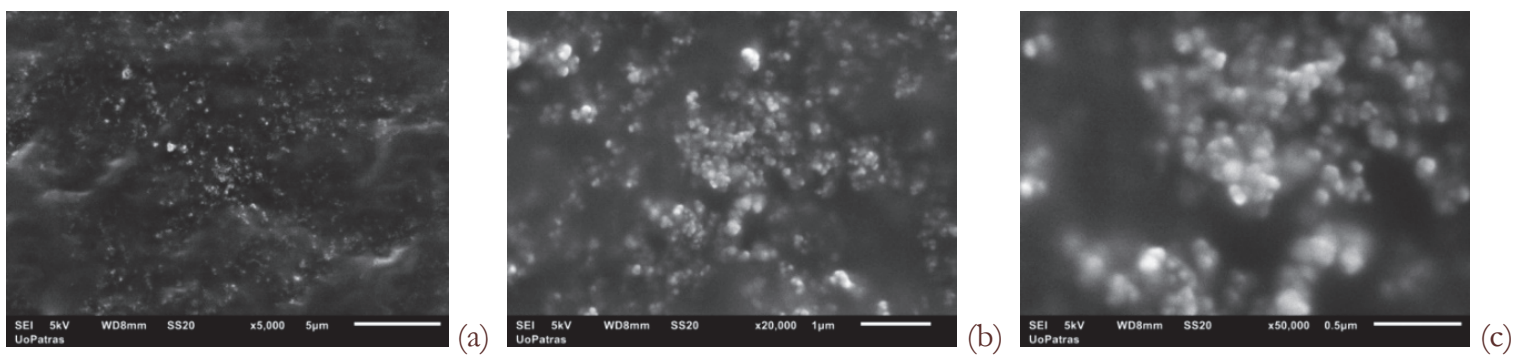

Figure 2: SEM photos of an area in the MWCNT/PP 2 wt\%이 specimen: a. x5,000, b. x20,000 and c. x50,000.
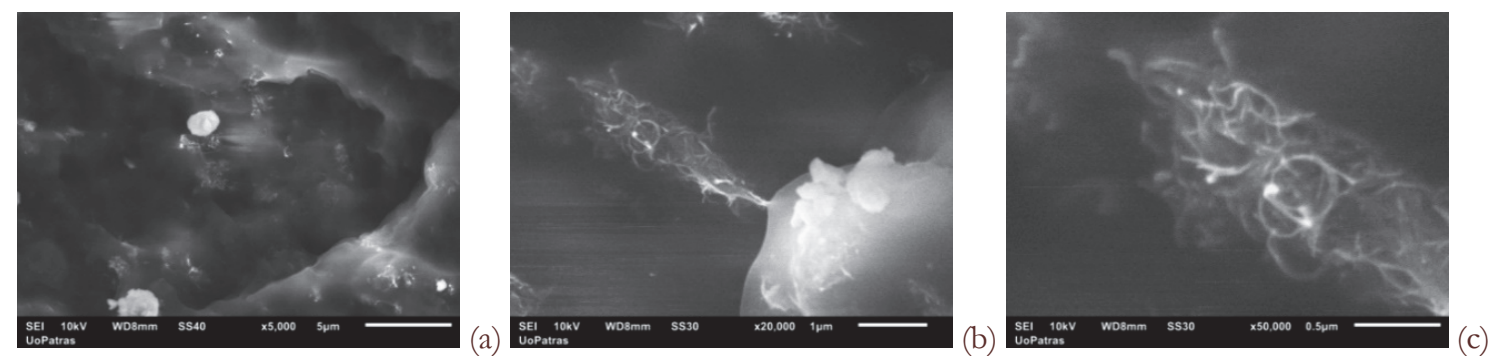

Figure 3: SEM photos of an area in the MWCNT/PP 2 wt\%_04 specimen: a. x5,000, b. x20,000 and c. x50,000.
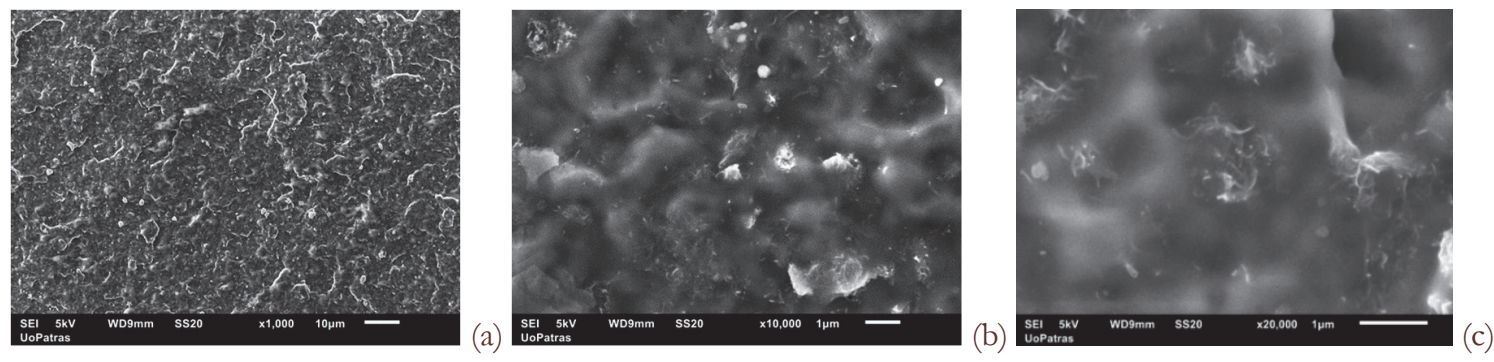

Figure 4: SEM photos of an area in the MWCNT/PP 5 wt\%_01 specimen: a. x1,000, b. x10,000 and c. x20,000.
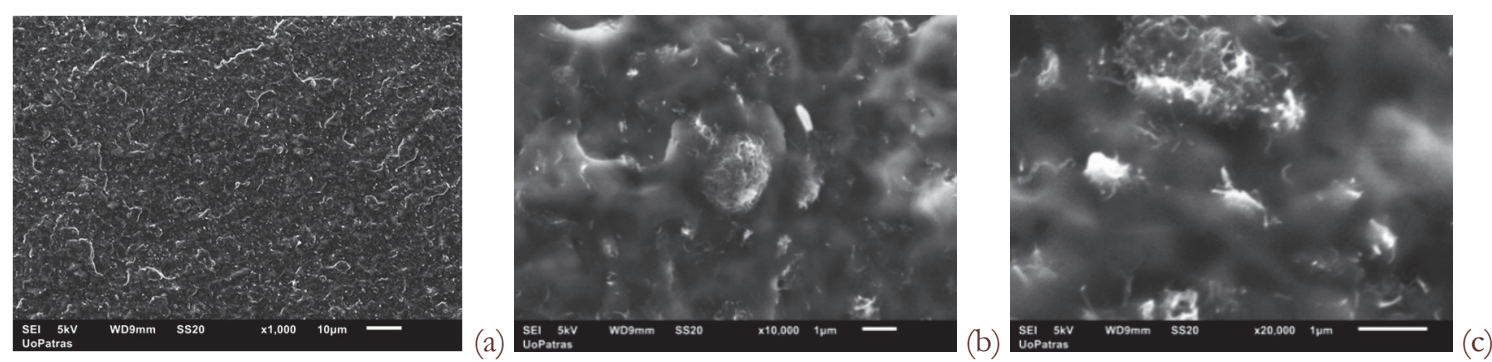

Figure 5: SEM photos of an area in the MWCNT/PP 5 wt\%이 specimen: a. x1,000, b. x10,000 and c. x20,000.

For the SEM tests two specimens were selected from each of the $2 \mathrm{wt} \%$ and $5 \mathrm{wt} \%$ materials, namely the MWCNT/PP 2 wt\%_03, MWCNT/PP 2 wt\%_04, MWCNT/PP 5 wt\%_01 and MWCNT/PP 5 wt\%_03 specimens. The selection was based on the large difference in their measured properties (Tab. 1). The SEM images from the MWCNT/PP 2 wt $\%$ _03 specimen are depicted in Fig. 2. In Fig. 2a, a good dispersion and wetting of the MWCNTs is observed. These are signs of efficient reinforcement as indicated by the large properties measured for the specific specimen. The magnification of the image in Fig. 2b makes the good dispersion of the MWCNTs more clear. Further increase in magnification (Fig. 2c) reveals minimal formation of MWCNT agglomerations and possible formation of MWCNT ropes. For the specimen MWCNT/PP $2 \mathrm{wt} \%$ _04, a sparse dispersion of MWCNTs and formation of agglomerations was observed (Fig. 3). This observation explains the smaller properties of specimen MWCNT/PP $2 \mathrm{wt} \%$ _04 compared to the MWCNT/PP $2 \mathrm{wt} \%$ _03 specimen. In the case of the MWCNT 5wt \% specimens, despite the good dispersion of the MWCNTs (Fig. 4a and Fig. 5a), formation of agglomerations was more intense due to the larger MWCNT content. In conclusion, the properties of the specimens are 
determined by the size of agglomerations. In cases where agglomerations of small size were developed, such as the MWCNT/PP $5 \mathrm{wt} \%$ _01 specimen (Figs. 4b and 4c), the measured properties are above average values, while in cases where agglomerations of large size were developed, such as the MWCNT/PP $5 \mathrm{wt} \% \_03$ specimen (Figs. 5b and $5 \mathrm{c}$ ), the measured properties are below the average values.

\section{Nanomechanical properties}

The relation (input functions) of displacement change versus time used in experiments is plotted in Fig. 6 below (schematic trapezoidal load-time $P=P(t)$ input function, 40 and 3 secs for conventional nanoindentation testing, respectively). Based on the above tension and SEM tests, MWCNT/PP $2 \mathrm{wt} \%$ specimens were selected for assessing the nanomechanical properties and grid mapping, due to the lower extent of agglomerations.

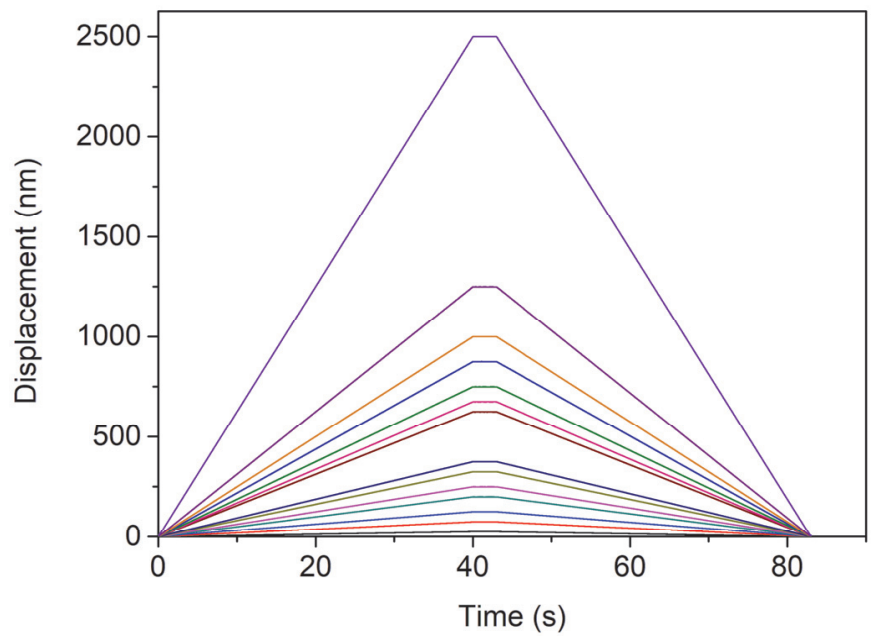

Figure 6: Load curves of MWCNT/PP $2 \mathrm{wt} \%$ specimen nanoindentation as a function of time

Scanning probe microscopy images of the sample surface are presented in Fig. 7; indent areas were carefully selected in order to minimize the measurement error.
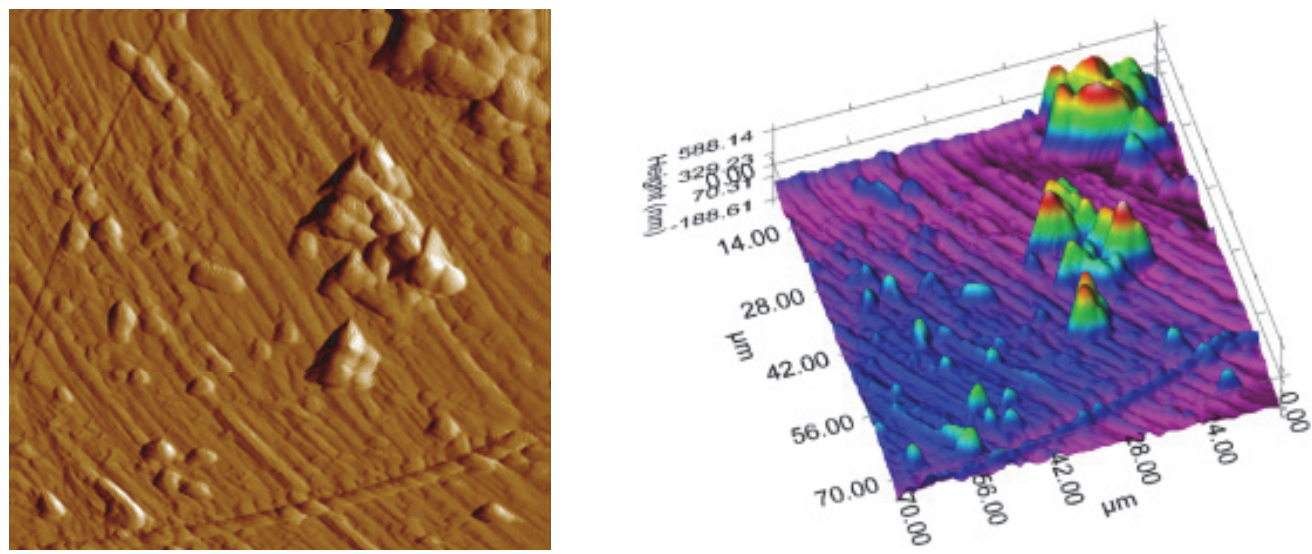

Figure 7: SPM images of different areas of MWCNT/PP $2 \mathrm{wt} \%$ specimen (area of $70 \times 70 \mu \mathrm{m}^{2}$ )

The load unload curves, the hardness and the elastic modulus as a function of displacement are presented in Figs. 8-9. Hardness and elastic modulus values of MWCNT $2 \mathrm{wt} \%$ specimen were found to deviate at surface region $(\sim 0-500 \mathrm{~nm})$, probably due to roundness of the tip and Indentation Size Effect (ISE), tending to reach a constant value of 0.11 and 1.8 $\mathrm{GPa}$, respectively. The reasons for the wide range in hardness and modulus values obtained from these nanoindentation measurements are currently unknown, but it is likely due to a combination of factors, e.g. graded surface structure due to CNTs concentration, adhesive forces between the tip and the sample etc. Due to the very low contact area between the indenter and the sample, very high stresses can be developed. The high hydrostatic pressure exerted by the surrounding 
material allows plastic deformation at room temperature when conventional mechanical testing only leads to fracture. It is revealed that some materials exhibit ISE, which shows an increase in hardness with decreasing applied load [27-29].

In Figs. 10 and 11, hardness (as resistance to applied load, contact pressure) and elastic modulus mapping [30,31], at 300nm of displacement for a grid of $70 \times 70 \mu \mathrm{m}^{2}$, is presented. Through projection, the resistance is clearly divided in 3 regions, namely the polymer (matrix), interface (region close to/between CNTs) and CNT bundle/agglomeration regions. The resistance deviates from low values (few $\mathrm{MPa}$ ) to $130 \mathrm{MPa}$.

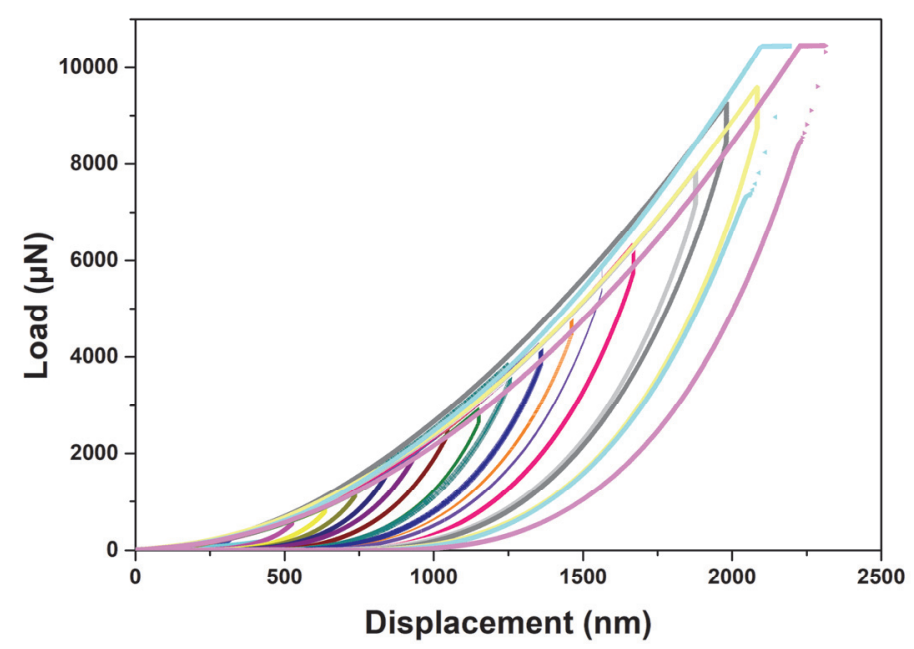

Figure 8: Load-unload curves as depth profile of PP with $2 \%$ CNTs

Higher stresses are related with higher H/E (hard materials); increased stress concentrations are developed towards the tip, whereas for low $\mathrm{H} / \mathrm{E}$ (soft materials), the stresses are found lower and are distributed homogeneously at the cross-section of the material [32,33]. $\mathrm{H} / \mathrm{E}$ is an index of resistance to wear; high $\mathrm{H} / \mathrm{E}$ is indicative of the increased wear resistance in a range of materials [33,34]: ceramic, metallic and polymeric. In Fig. 12, alter of $\mathrm{H} / \mathrm{E}$ slope denotes the surface region (up to $\sim 500 \mathrm{~nm}$ ); for greater displacements, $\mathrm{H} / \mathrm{E}$ tends to reach the value of 0.065 .

In Fig. 13, the contact pressure (as resistance to applied load) mapping, at 300nm of displacement for a grid of $70 \mu \mathrm{m}^{2}$ for polypropylene with $2 \% \mathrm{CNTs}$, is presented. Through projection, the resistance is clearly divided in 3 regions, namely the polymer (matrix), interface (region close to/between CNTs) and CNT bundle/agglomeration regions. The resistance deviates from low values (few $\mathrm{MPa}$ ) to $1.8 \mathrm{GPa}$. With this analysis, nanoindentation is considered as a potential technique for inline fast characterisation in the field of composites. As nanomechanical integrity of the (nano-enabled) composites is a key factor in manufacturing failure free product (technology which progressively scales down into the micron/nanometer regime), a reliable nanoindentation protocol is of need in quality control.
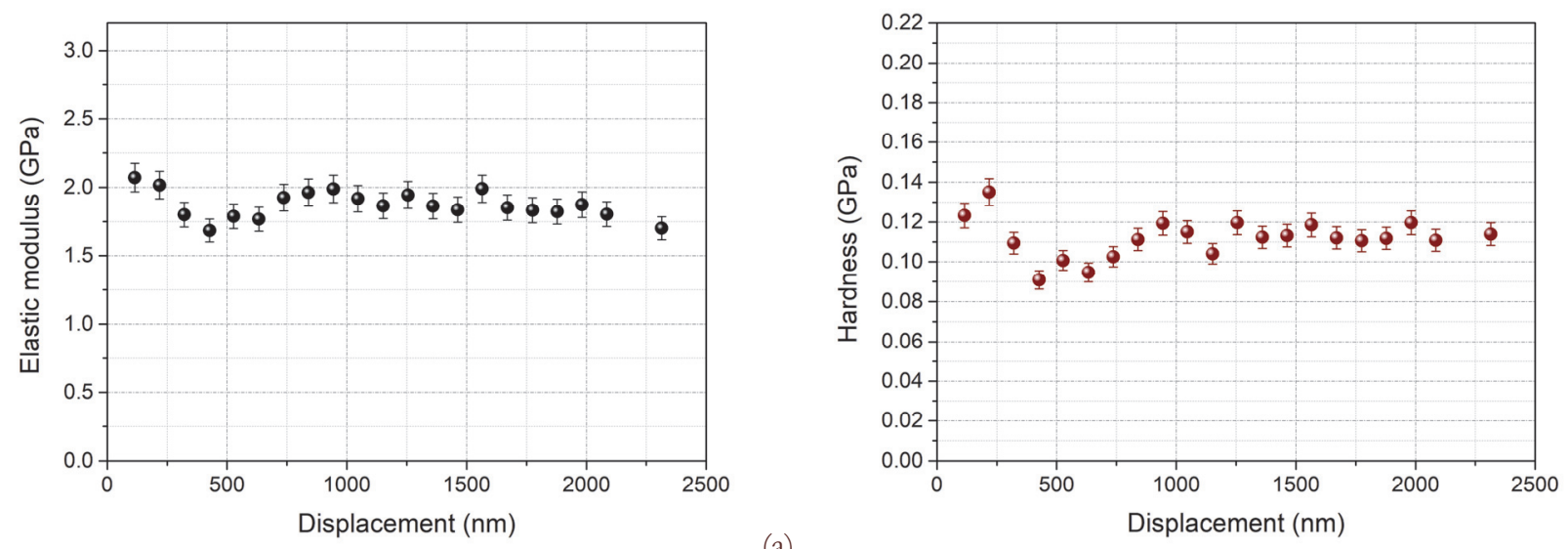

(a)

Figure 9: a) Elastic modulus and b) hardness values of the sample as a function of displacement, for MWCNT/PP $2 \mathrm{wt} \%$ specimen. 


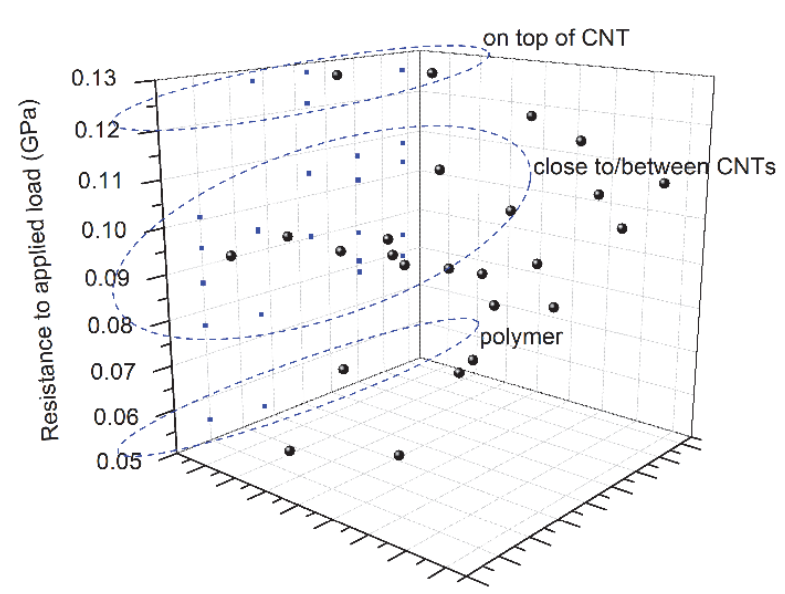

Figure 10: Resistance to applied load mapping, at 300nm of displacement for a grid of $70 \times 70 \mu \mathrm{m}^{2}$ for MWCNT/PP $2 \mathrm{wt} \%$ specimen.

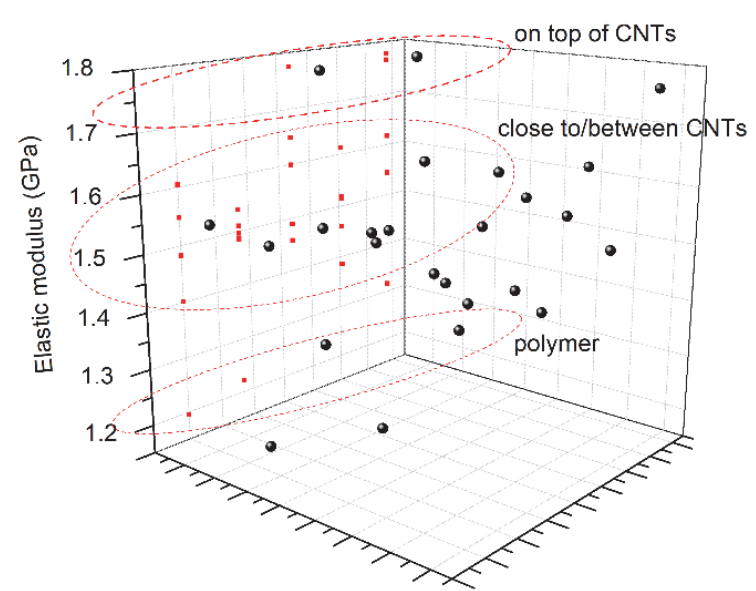

Figure 11: Elastic modulus mapping, at $300 \mathrm{~nm}$ of displacement for a grid of $70 \times 70 \mu \mathrm{m}^{2}$ for MWCNT/PP $2 \mathrm{wt} \%$ specimen.

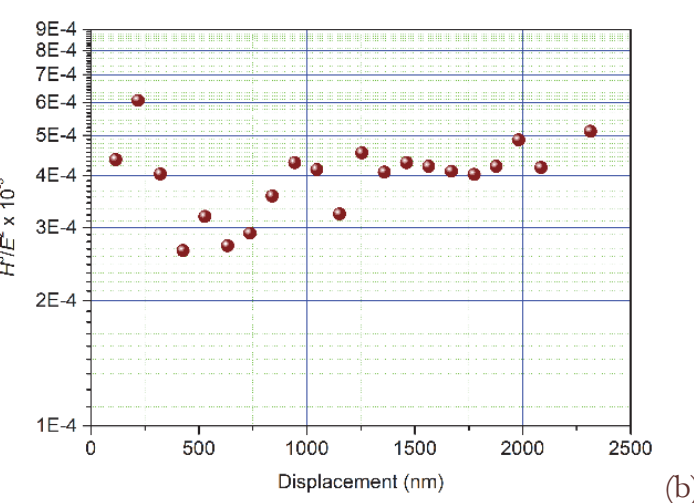

(a)

Figure 12: (a) $H / E$ and (b) $H^{3} / E^{2}$ of MWCNT/PP $2 \mathrm{wt} \%$ specimen.

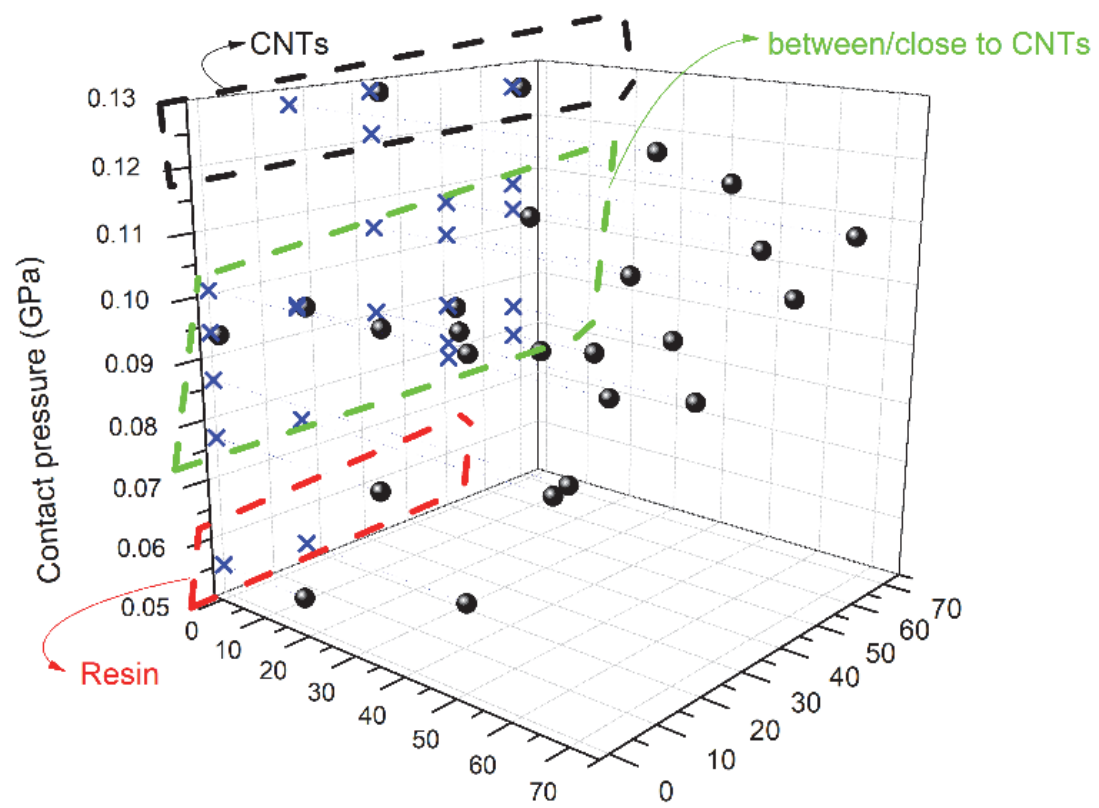

Figure 13: Contact pressure (as resistance to applied load) mapping, at 300nm of displacement for a grid of $70 \mu \mathrm{m}^{2}$ for polypropylene with $2 \%$ CNTs. 


\section{CONCLUSIONS}

I $\mathrm{n}$ the present paper, the mechanical and nanomechanical properties of multi-walled carbon nanotube-reinforced polypropylene (MWCNT/PP) nanocomposite were investigated through tension tests (conducted on $2 \mathrm{wt} \%$ and 5 $\mathrm{wt}^{\%} \%$ specimens) and nanoindentation tests (conducted on $2 \mathrm{wt} \%$ specimens). From the methodology of the paper and the discussion of the experimental results, we conclude that:

- Filling the PP material by MWCNTs enhances the tensile behavior and increases both the Young's modulus and the yield stress by more than $20 \%$. The tensile properties of the nanofilled PP material increase with increasing the MWCNT content.

- For most of nanofilled specimens for both MWCNT contents a good dispersion of MWCNTs was observed. In the specimens for which this was not the case, smaller properties were obtained due to formation of agglomerations.

- Based on the measured resistance through applied load nanoindentation mapping, the material is clearly divided in 3 regions, namely the polymer (matrix), interface (region close to/between CNTs) and CNT bundle/agglomeration regions. The resistance in these regions deviates from low values (few MPa) to $130 \mathrm{MPa}$.

- Based on the evaluated $\mathrm{H}^{3} / \mathrm{E}^{2}$ ratio it is concluded that the addition of CNTs in PP results in enhanced elasticity, while the surface region appears as more plastic.

\section{REFERENCES}

[1] Tserpes, K.I., Chanteli A. (2013). Parametric numerical evaluation of the effective elastic properties of carbon nanotubereinforced polymers, Composite Structures,99, pp. 366-374. DOI: 10.1016/j.compstruct.2012.12.004.

[2] Chanteli, A., Tserpes, K. (2015). Finite element modeling of carbon nanotube agglomerates in polymers, Composite Structures, 132, pp. 1141-1148. DOI: 10.1016/j.compstruct.2015.07.033.

[3] Kim, J., Seong, D., Kang, T., Youn, J. (2006). Effects of surface modification on rheological and mechanical properties of CNT/epoxy composites, Carbon, 44, pp. 1898-1905. DOI: 10.1016/j.carbon.2006.02.026.

[4] Pegel, S., Potschke, P., Villmow, T., Stoyan, D., Heinrich, G. (2009). Spatial statistics of carbon nanotube polymer composites, Polymer, 5, pp. 2123-2132. DOI: 10.1016/j.polymer.2009.02.030.

[5] Al Safee, A., Al-Ajaj, I., Khalil, A. (2014). Electrical conductivity of untreated multiwalled carbon nanotube/epoxy composites, IJAIEM, 3(3), pp. 22-31. DOI: 10.1002/pen.21996.

[6] Selmi, A., Friebel, C., Doghri, I., Hassis, H. (2007). Prediction of the elastic properties of single walled carbon nanotubes reinforced polymers, Compos Sci Tech, 67, pp. 2071-2084. DOI: 10.1016/j.compscitech.2006.11.016.

[7] Giraldo, L., Lopez, B., Bostow, W. (2009). Effect of the type of carbon nanotubes on tribological properties of polyamide, Polym Eng Sci, 49, pp. 896-902. DOI: 10.1002/pen.21386.

[8] Gojnya, F., Wichmann, M., Köpke, U., Fiedler, B., Schulte, K. (2004). Carbon nanotube-reinforced epoxy-composites: enhanced stiffness and fracture toughness at low nanotube content, Comp Sci Tech, 64(15), pp. 2363-2371. DOI: 10.1016/j.compscitech.2004.04.002.

[9] Kao, C., Young, R. (2010). Assessment of interface damage during the deformation of carbon nanotubes composites, J Mater Sci, 45, pp. 1425-1431. DOI: 10.1007/s10853-009-3947-0.

[10] Lagoudas, D.C., Thakre, P.R., Benzerga, AA. (2012). Nanoindentation of CNT Reinforced Epoxy Nanocomposites. Department of Aerospace Engineering, Texas A \& M University, Texas.

[11] dos Santos, M.N., Opelt, C.V., Lafratta F.H., Lepienski, C.M., Pezzin, S.H. and Coelho, L.A.F. (2011). Thermal and mechanical properties of a nanocomposite of a photocurable epoxy-acrylate resin and multiwalled carbon nanotube, Mater. Sci. Eng. A., 528 (13-14), pp. 4318-4324. DOI: 10.1016/j.msea.2011.02.036.

[12] Li, X., Gao, H., Scrivens, W.A., Fei, D., Xu, X., Sutton, M.A., Reynolds, A.P., and Myrick, M.L. (2004). Nanomechanical Characterization of Single-Walled Carbon Nanotube-Reinforced Epoxy Composites, Nanotechnology, 15(11) pp.14161423. DOI: $10.1088 / 0957-4484 / 15 / 11 / 005$.

[13] Cadek, M., Coleman, J.N. and Barron, V. (2002). Morphological and mechanical properties of carbon-nanotubereinforced semicrystalline and amorphous polymer composites, Appl. Phys. Lett., 81(27), pp. 5123-5125. DOI: 10.1063/1.1533118.

[14] Liu, L. and Wagner, H.D. (2005). Rubbery and glassy epoxy resins reinforced with carbon nanotubes, Compos. Sci. Technol., 65 (11-12), pp. 1861-1868. DOI: 10.1016/j.compscitech.2005.04.002. 
[15] Chafidz, A., Rengga, W. D. P., Khan, R., Kaavessina, M., Almutlaq, A. M., Almasry, W. A. and Ajbar, A. (2017). Polypropylene/multiwall carbon nanotubes nanocomposites: Nanoindentation, dynamic mechanical and electrical properties, J. Appl. Polym. Sci., 134(37), pp. 45293. DOI: 10.1002/app.45293.

[16] NANOCYL S.A. (2009). PLASTICYLTM PP2001 Technical Data Sheet, 08, pp.1-4. Available at: http://www.nanocyl.com/wp-content/uploads/2015/11/DM-TSD-02-TDS-PLASTICYL-PP-2001-V08.pdf.

[17] ASTM D638-01, Standard Test Method for Tensile Properties of Plastics, ASTM International, West Conshohocken, PA, 2014, www.astm.org.

[18] Koumoulos, E.P., Dragatogiannis, D.A., Charitidis, C.A. (2014). Nanomechanical properties and deformation mechanism in metals, oxides and alloys, In: Nanomechanical Analysis of High Performance Materials, Netherlands: Springer, pp. 123-152. DOI: 10.1007/978-94-007-6919-9.

[19] Koumoulos, E.P., Charitidis, C.A., Papageorgiou, D.P., Papathanasiou, A.G., Boudouvis, A. (2012). Nanomechanical and nanotribological properties of hydrophobic fluorocarbon dielectric coating on tetraethoxysilane for electrowetting applications, Surface and Coatings Technology, 206 (19-20), pp. 3823-3831. DOI: 10.1016/j.surfcoat.2012.01.034.

[20] Charitidis, C.A., Koumoulos, E.P. and Dragatogiannis, D.P. (2013). Nanotribological Behavior of Carbon Based Thin Films: Friction and Lubricity Mechanisms at the Nanoscale, Lubricants, 1(2), pp. 22-47. DOI: 10.3390/lubricants 1020022 .

[21] Koumoulos, E.P., Charitidis, C.A., Papageorgiou, D.P., Papathanasiou, A.G. Boudouvis, A.G. (2012). Surface and Coatings Technology, (19-20), pp. 3823-3831.

[22] Oliver, W. C. and Pharr, G. M. (1992). An improved technique for determining hardness and elastic modulus using load and displacement sensing indentation experiments, J. Mater. Res., 7(06), pp. 1564-1583. DOI: 10.1557/JMR.1992.1564.

[23] Sneddon, I. N. (1948). Boussinesq's problem for a rigid cone, Mathematical Proceedings of the Cambridge Philosophical Society, 44(04), pp. 492-507. DOI: 10.1017/S0305004100024518.

[24] Huang, L., Lu, J. and Troyon, M. (2006). Nanomechanical properties of nanostructured titanium prepared by SMAT, Surface and Coatings Technology, 201(1-2), pp. 208-213. DOI: 10.1016/j.surfcoat.2005.11.090.

[25] King, R. B. (1987). Elastic analysis of some punch problems for a layered medium, International Journal of Solids and Structures, 23(12), pp.1657-1664. DOI: 10.1016/0020-7683(87)90116-8.

[26] Bei, H., George, E. P., Hay, J. L. and Pharr, G. M. (2005). Deformation during Nanoindentation, Phys. Rev. Let., 95(4), pp. 045501(1-4). DOI: 10.1103/Phys. Rev. Lett.95.045501.

[27] Charitidis, C.A. and Koumoulos, E.P. (2012) Nanomechanical properties and nanoscale deformation of PDMS nanocomposites, Plastics, Rubber and Composites, 41 (2), pp. 88-93. DOI: 10.1179/1743289810Y.0000000037.

[28] Koumoulos, E.P., Parousis, T., Trompeta, A.-F.A., Kartsonakis, I.A., Charitidis, C.A. (2016). Investigation of MWCNT addition into poly-dimethylsiloxane-based coatings, Plastics, Rubber and Composites, 45 (3), pp. 106-117. DOI: 10.1080/14658011.2016.1144376.

[29] Koumoulos, E.P., Jagadale, P., Lorenzi, A., Tagliaferro, A., Charitidis, C.A. (2015). Evaluation of surface properties of epoxy-nanodiamonds composites, Composites Part B: Engineering, 80, pp. 27-36.

DOI: 10.1016/j.compositesb.2015.05.036.

[30] Koumoulos, E.P. and Charitidis, C.A. (2017). Surface analysis and mechanical behaviour mapping of vertically aligned CNT forest array through nanoindentation, Applied Surface Science, 396, pp. 681-687. DOI: $10.1016 /$ j.apsusc.2016.11.008.

[31] Koumoulos, E.P., Dragatogiannis, D.A., Kartsonakis, I.A., Karaxi, E., Kehagias, T., Charitidis, C.A. (2016). Nanomechanical performance of protective coatings reinforced with core/shell composite materials, International Journal of Structural Integrity, 7(5), pp.671-689. DOI: 10.1108/IJSI-10-2015-0051.

[32] Leyland, A. and Matthews, A. (2004). Design criteria for wear-resistant nanostructured and glassy-metal coatings, Surf. Coat. Technol., 177-178, pp. 317-324. DOI: 10.1016/j.surfcoat.2003.09.011.

[33] Leyland, A. and Matthews, A. (2007). Optimization of Nanostructured Tribological Coating, In: Nanostructured Coatings, Springer: New York, NY, USA, pp. 511-538.

[34] Oberle, T.L. (1951). Properties influencing wear of metals, J. Met., 3, 438-439.

[35] Halling, J. (1982). Surface films in tribology, Tribologia, 1, pp. 15-23.

[36] Leyland, A. and Matthews, A. (2000). On the significance of the H/E ratio in wear control: A nanocomposite coating approach to optimised tribological behavior, Wear, 246 (1-2), pp. 1-11. DOI: 10.1016/S0043-1648(00)00488-9.

[37] Koumoulos, E.P., Jagdale, P., Kartsonakis, I.A., Giorcelli, M., Tagliaferro, A., Charitidis, C.A. (2014). Carbon Nanotube/Polymer Nanocomposites: A Study on Mechanical Integrity through Nanoindentation, Polym. Compos., 36(8), pp. 1432-1446. DOI: 10.1002/pc.23049. 
[38] Trompeta, A.-F.A., Koumoulos, E.P., Kartsonakis, I.A., Charitidis, C.A. (2017). Advanced characterization of byproduct carbon film obtained by thermal chemical vapor deposition during CNT manufacturing, Manufacturing Review, 4, 7. DOI: 10.1051/mfreview/2017006.

[39] Koumoulos, E.P. and Charitidis, C.A. (2017). Lubricity Assessment, Wear and Friction of CNT-Based Structures in Nanoscale, Lubricants, 5 (2), 18. DOI: 10.3390/lubricants5020018. 